IP Periodica Polytechnica

Transportation Engineering

47(1), pp. 25-28, 2019

https://doi.org/10.3311/PPtr.9452

Creative Commons Attribution (i)

RESEARCH ARTICLE

\section{Multifunctional Signal Generator for Calibration System of Jet Engine Exhaust Gas Temperature Measurement}

\author{
Premysl Janu ${ }^{1 *}$, Sang Van Doan ${ }^{1}$
}

Received 09 May 2016; accepted 19 December 2016

\begin{abstract}
One of the most important systems of an aircraft jet engine is exhaust gas temperature measurement system that ensure right function of the engine. Temperature of the gas flowing from the engine turbine is quite high. There is one way, how to measure high temperature and it is by thermocouple. So the main aim of the paper is to describe creation and correct function analysis of a thermocouple simulator. Thermocouple generates very low voltage depending on a temperature that ranges from units micro-volts to several tens of millivolts. Generating of such low voltage using simulator is not easy, because this voltage may move at levels of noise. Voltage generation is performed by digital-analogue converter, which is controlled by a microcontroller via SPI bus. The generated voltage is further reduced to a level corresponding to the voltage output of the thermocouple. Several calibration waveforms are performed belonging to appropriate thermocouple type for multifunctional use. Only positive temperatures are generated, because exhaust gas temperature measurement system is aimed at high temperatures. The power supply circuit offers two options. It is supply from accumulator for its portability or from the laboratory power supply. Surface mounted devices are selected in terms of module miniaturization. The newest device base is chosen for modern design of the module. The temperature waveform is generated by the way of polynomial approximation with correction. Dependence of real generated voltage on the voltage, which is defined by appropriate thermocouple type standard and errors evaluation, is used as a proof of proper function.
\end{abstract}

\section{Keywords}

thermocouple, thermocouple simulator, exhausts gas temperature, jet engine, calibration system, relative error, analysis

\section{Introduction}

One of the most important jet engines characteristics is thrust. There are two factors how to achieve high jet engine thrust. One of them is high compressed air behind last stage of a compressor and the second is high gas temperature before a turbine. The high combustion temperature also has an effect on amount of incinerated oxygen from an air stream. The gas temperature before turbine in today's jet engines does not exceed $1500{ }^{\circ} \mathrm{C}$. All air oxygen is not burned at such temperatures, thus additional burning can work. The main aim of designers is to reach temperature value before turbine approximately $2250{ }^{\circ} \mathrm{C}$, when all air oxygen is burned and additional burning is not required. But such value of temperature is future aim, because now materials that are resistant of such temperature in the long term are not known. Right function of jet engine required exhaust gas temperature measurement. One way of contact temperature measuring is by thermocouple. Thermocouple measurement system requires periodical calibration. Very important part of the thermocouple calibration system is signal generator (thermocouple simulator). The following parts of the paper are devoted to design and correct function verification of signal generator of thermocouple calibration system.

\section{Structure Performance of Signal Generator}

The signal generator serves as reference device - thermocouple simulator. Thermocouple produces very low voltage, which is dependent on temperature. Main aim was to create generator simulating behaviour of real thermocouple. It is multifunctional generator that simulates several types of thermocouples (thermocouple standards). The generator is specialized for calibration of exhaust gas temperature measurement system. So that it generates signal only for positive temperature, negative temperature is not significant for this application. Block diagram of the generator is in the Fig. 1.

\footnotetext{
${ }^{1}$ Department of Radar Technology

Faculty of Military Technology,

University of Defence

66210 Brno, Czech Republic

*Corresponding author, e-mail: premysl.janu@unob.cz
} 


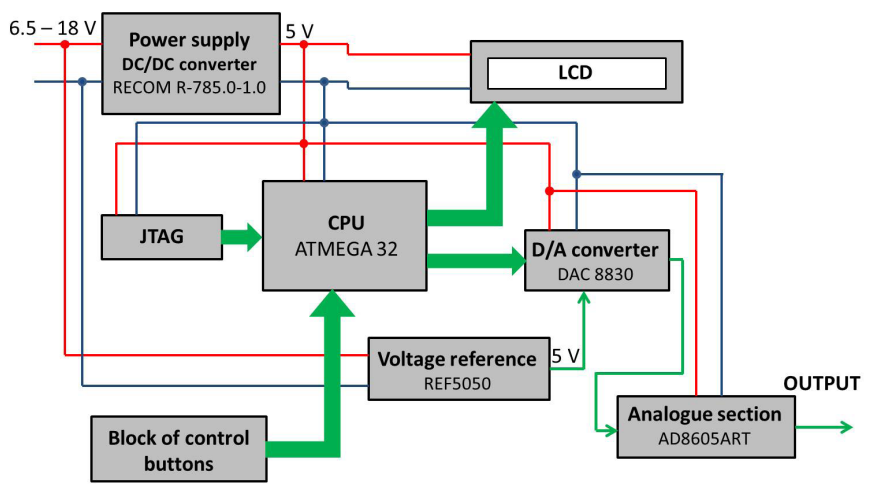

Fig. 1 Block diagram of the generator

Heart of the module is microcontroller ATMEGA 32, that controls all operation. It receives information from the block of control buttons, sends data to the D/A converter and depicts important information on LCD. Complete operation algorithm is written into the microcontroller through JTAG interface. Power supply feeds all devices of the module. Important device in the power supply part is DC/DC converter RECOM R-785.01.0 , that transforms voltage at quite wide range $6.5-18 \mathrm{~V}$ to the voltage at a value of $5 \mathrm{~V}$. The range offers two way of supply. One of them is battery or accumulator for mobility ensuring. Second one is laboratory supply. Block of control buttons serves for selection of thermocouple type and for temperature setting, which is depicted on the LCD. There are six buttons for temperature setting. Two buttons are for hundreds of Celsius degree setting up and down, two are for tens setting and two are for units setting. One button is for thermocouple type selection. Block voltage reference REF 5050 ensures accurate reference level of $5 \mathrm{~V}$ for $\mathrm{D} / \mathrm{A}$ converter. D/A converter is controlled by ATMEGA 32 via SPI bus and generates signal at the range of $0-5 \mathrm{~V}$, that corresponds to a temperature waveform of given thermocouple. 16 bit DAC 8830 is used at this application. Analogue section reduces the voltage generated by D/A converter to the real voltage corresponding to the particular thermocouple type standard. Single supply operational amplifier AD8605ART is used in this part. Voltage on OUTPUT signal corresponds to the certain thermocouple type standard. Real scheme is used from simulation application Proteus in which circuit function was tested and is in the Fig. 2.

Up-to-date devices were selected for the application. Most of them are made by SMD technology for the module miniaturization. The module is produced in form of PCB.

\section{Algorithm of the Signal Generator Control}

Very important part of the module is the block of control buttons. These buttons are for selection of thermocouple type and for temperature setting, which is depicted on the LCD. Microcontroller generates data for digital-analogue converter according set temperature. There are two possibilities how to generate data for the digital-analogue converter. One of them is to save dependence of a voltage on temperature according to individual thermocouple standard to the microcontroller memory and then usually select voltage corresponding to the temperature and send it to the digital-analogue converter. This method is quite fast for microcontroller but require very much memory space. This is multifunctional generator that enables to simulate seven types of thermocouples (K, E, J, N, R, S and B). So this method would require saving dependence of all these thermocouple types to the microcontroller memory. Second method is to apply polynomial approximation from all dependences of voltage on temperature and corresponding voltage calculate in the microcontroller and send it to the digital-analogue converter. This method is slower for microcontroller but does not require much space in the microcontroller memory. This method is used in the paper.

\section{Function Verification and Errors Analysis}

The control algorithm such as right information acquisition from buttons, right depiction of a temperature and thermocouple type on LCD, right voltage calculation, right digital-analogue converter control and right voltage conversion was verified by simulation environment called Proteus. The simulation scheme is in the Fig. 2. Real voltage value verification was performed in laboratory conditions. Experimental workplace was assembled according the block scheme in the Fig. 3.

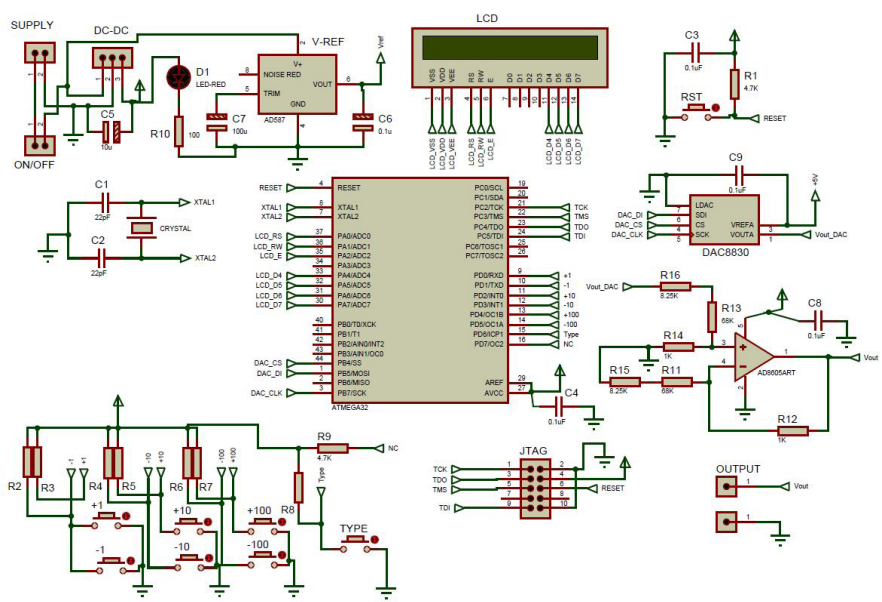

Fig. 2 Real scheme of the thermocouple simulator

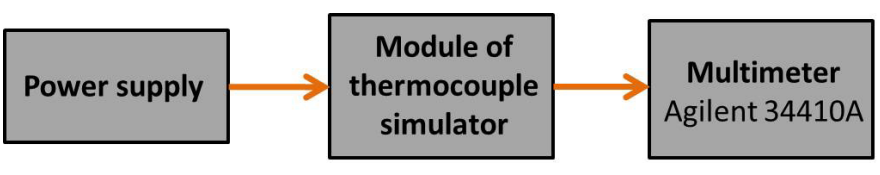

Fig. 3 Block scheme of the experimental workplace

The experimental workplace consisted of produced module of thermocouple simulator, which was fed by laboratory power supply. High accurate multimeter Agilent 34410A was used for measurement of generated low voltage. This multimeter is able to measure voltage at a value of units of microvolts with relative error $\pm(0.0030 \%$ of reading +0.0030 of range $)$. Real experimental workplace is in Fig. 4. 


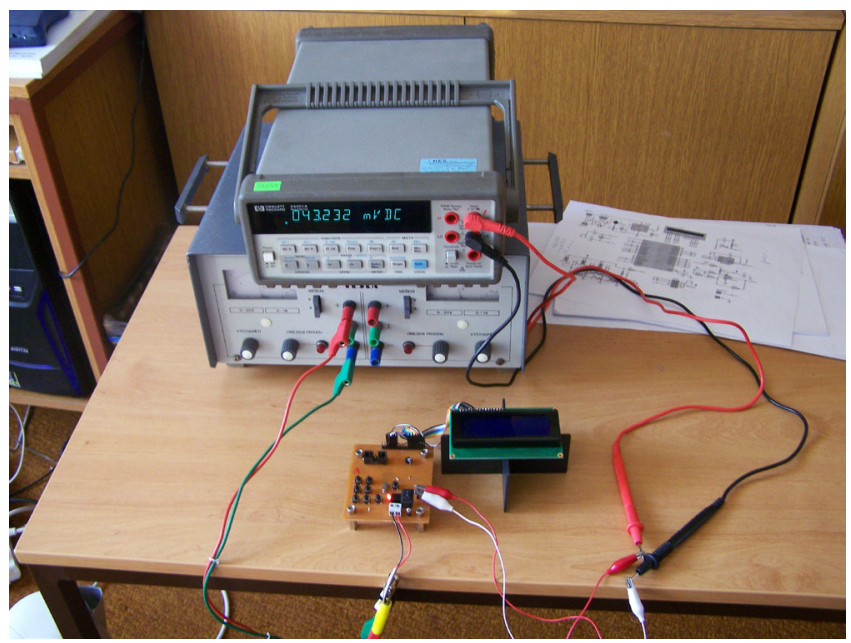

Fig. 4 Experimental workplace

Voltage generation in a dependence on a temperature is solved by polynomial approximation method. Several polynomials were analysed (linear, second up to sixth degree). Higher polynomial degrees were not significant. Sixth degree polynomial fit the best to individual thermocouple standards. There are applied polynomials:

Thermocouple type $\mathrm{K}$

$$
\begin{aligned}
U= & -7.61253600 \cdot 10^{-18} \cdot t^{6}+3.43859585 \cdot 10^{-14} \cdot t^{5} \\
& -5.82837884 \cdot 10^{-11} \cdot t^{4}+4.14368934 \cdot 10^{-8} \cdot t^{3} \\
& -9.81195806 \cdot 10^{-6} \cdot t^{2}+4.11248613 \cdot 10^{-2} \cdot t
\end{aligned}
$$

Thermocouple type B

$$
\begin{aligned}
U & =-8.94667945 \cdot 10^{-20} \cdot t^{6}+3.64818919 \cdot 10^{-16} \cdot t^{5} \\
& -4.65061177 \cdot 10^{-13} \cdot t^{4}-4.06472658 \cdot 10^{-10} \cdot t^{3} \\
& +5.72492019 \cdot 10^{-6} \cdot t^{2}-2.34620629 \cdot 10^{-4} \cdot t \\
& -1.24169037 \cdot 10^{-4}
\end{aligned}
$$

Thermocouple type E

$$
\begin{aligned}
U= & -1.03086809 \cdot 10^{-18} \cdot t^{6}-2.81861565 \cdot 10^{-15} \cdot t^{5} \\
& +2.59350063 \cdot 10^{-11} \cdot t^{4}-5.87345131 \cdot 10^{-8} \cdot t^{3} \\
& +5.47176208 \cdot 10^{-5} \cdot t^{2}+5.83061685 \cdot 10^{-2} \cdot t
\end{aligned}
$$

Thermocouple type $\mathrm{J}$

$$
\begin{aligned}
U & =8.54453767 \cdot 10^{-17} \cdot t^{6}-3.16196529 \cdot 10^{-13} \cdot t^{5} \\
& +4.25894859 \cdot 10^{-10} \cdot t^{4}-2.53367011 \cdot 10^{-7} \cdot t^{3} \\
& +6.85996437 \cdot 10^{-5} \cdot t^{2}+4.75931224 \cdot 10^{-2} \cdot t
\end{aligned}
$$

Thermocouple type $\mathrm{N}$

$$
\begin{aligned}
U= & -6.74080023 \cdot 10^{-19} \cdot t^{6}+1.17331474 \cdot 10^{-15} \cdot t^{5} \\
& +3.92385466 \cdot 10^{-12} \cdot t^{4}-1.69984937 \cdot 10^{-8} \cdot t^{3} \\
& +2.32553528 \cdot 10^{-5} \cdot t^{2}+2.55747135 \cdot 10^{-2} \cdot t
\end{aligned}
$$

Thermocouple type $\mathrm{R}$

$$
\begin{aligned}
U= & 9.39714543 \cdot 10^{-19} \cdot t^{6}-5.87895583 \cdot 10^{-15} \cdot t^{5} \\
& +1.37911599 \cdot 10^{-11} \cdot t^{4}-1.60658431 \cdot 10^{-8} \cdot t^{3} \\
& +1.22929559 \cdot 10^{-5} \cdot t^{2}+5.42585488 \cdot 10^{-3} \cdot t
\end{aligned}
$$

Thermocouple type $\mathrm{S}$

$$
\begin{aligned}
U= & 9.26875406 \cdot 10^{-19} \cdot t^{6}-5.75889041 \cdot 10^{-15} \cdot t^{5} \\
& +1.34489012 \cdot 10^{-11} \cdot t^{4}-1.54126452 \cdot 10^{-8} \cdot t^{3} \\
& +1.08253490 \cdot 10^{-5} \cdot t^{2}+5.55627752 \cdot 10^{-3} \cdot t
\end{aligned}
$$

$\mathrm{U}$ is voltage and $\mathrm{t}$ is temperature.

Relative error was chosen as an identification parameter of right function (right voltage generation) of the module. Analysis of individual polynomial itself aimed at relative errors was performed first. Dependence of relative errors on a temperature is in Fig. 5.

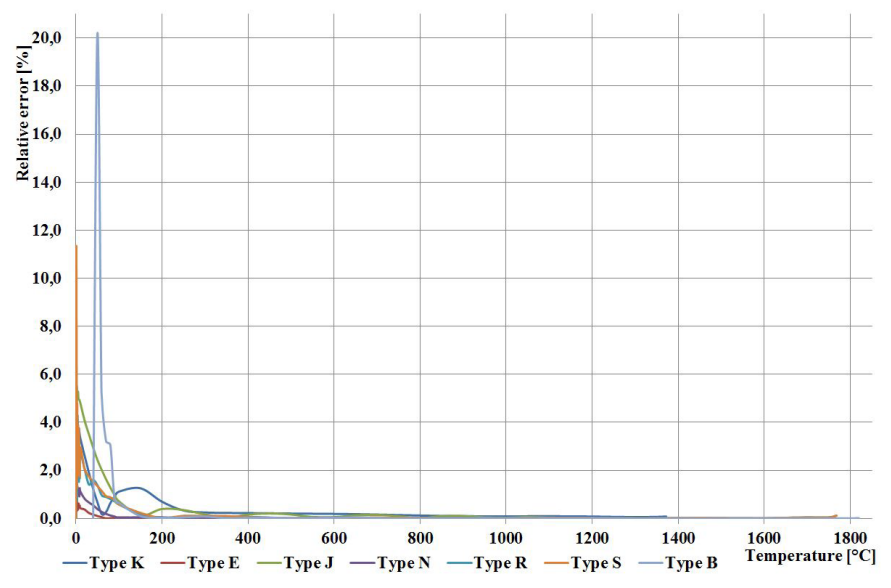

Fig. 5 Dependence of relative errors on a temperature of individual thermocouple types polynomial

Relative error is quite high in a temperature range from $0{ }^{\circ} \mathrm{C}$ to approximately $300{ }^{\circ} \mathrm{C}$. Maximal error shows thermocouple type $\mathrm{B}$ and it is $20.174 \%$. Minimal error at this temperature range performs thermocouple type $\mathrm{E}$ and it is $1.083 \%$. Relative error at a range from $300{ }^{\circ} \mathrm{C}$ to $750{ }^{\circ} \mathrm{C}$ is lower than $0.300 \%$. Just this area is very important for right function of jet engine. At a temperature range from $750{ }^{\circ} \mathrm{C}$ to maximum for individual thermocouple type relative error is lower than $0.125 \%$.

Produced module with this polynomials applied was verified after this analysis. Dependence of relative errors on a temperature of individual thermocouple types of real module is in Fig. 6.

Graphs for individual thermocouples are different. Maximal relative error at a range from $0{ }^{\circ} \mathrm{C}$ to $300{ }^{\circ} \mathrm{C}$ shows thermocouple type $\mathrm{R}$ and it is $20.000 \%$. Minimal error at this temperature range reaches thermocouple type $\mathrm{E}$ too and it is $1.695 \%$. At a temperature range from $300{ }^{\circ} \mathrm{C}$ to $750{ }^{\circ} \mathrm{C}$ all thermocouple types achieve very good results. Relative error is lower than $0.350 \%$. At a temperature range from $750{ }^{\circ} \mathrm{C}$ to maximal temperature relative error does not exceed $0.150 \%$.

Quite interesting was comparison of a relative error of polynomials and real module. Results of the analysis are represented on the most significant thermocouple type J and are in Fig. 7.

Polynomial is better than real module at a temperature range

(6) from $0{ }^{\circ} \mathrm{C}$ to $150{ }^{\circ} \mathrm{C}$. Maximal relative error reaches $5.487 \%$ whereas module has maximal relative error $8.000 \%$. On the 
other side module shows better characteristic in an interest area from $150{ }^{\circ} \mathrm{C}$ to $750{ }^{\circ} \mathrm{C}$. But at a range from $750{ }^{\circ} \mathrm{C}$ to $1200{ }^{\circ} \mathrm{C}$ polynomial and module shows nearly the same characteristics. The module shows better characteristics from a global viewpoint.

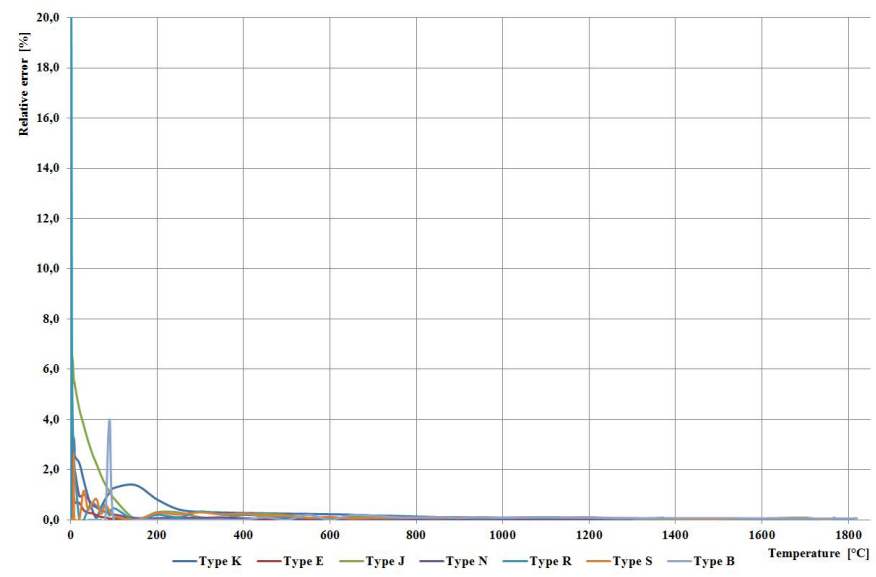

Fig. 6 Dependence of relative errors on a temperature of individual thermocouple types of real module

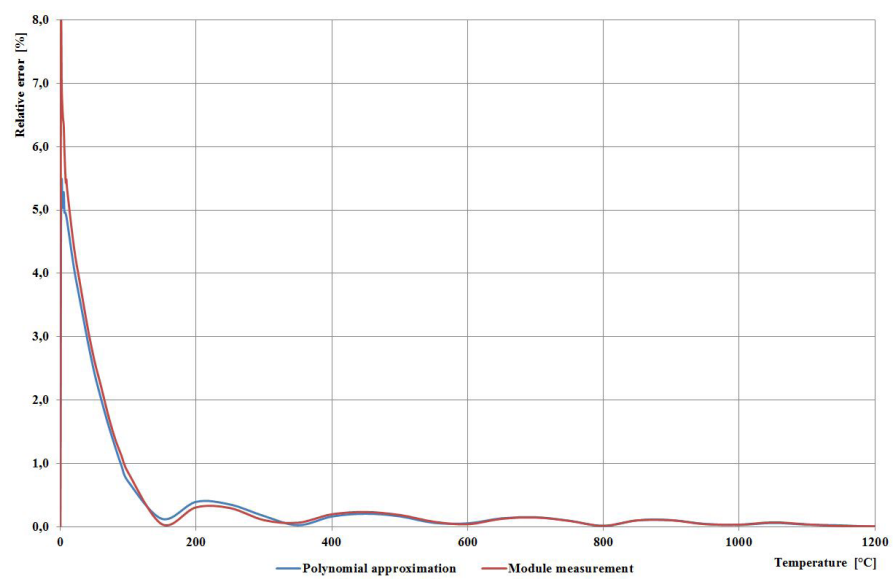

Fig. 7 Comparison results of a relative error of polynomial and real module

\section{Conclusion}

The paper presents design of the multifunctional thermocouple simulator. Structure of it is described. Module is made from up-to-date electronic devices and by SMD technology for the module miniaturization. Algorithm of control and low voltage generation is introduced. Low voltage corresponding to the thermocouple standards is generated by polynomial approximation method. The most important part of the paper is module verification. Relative error was selected as a significant parameter for verification. Temperature dependence of relative error of polynomial approximation itself and real module is performed.
Relative error of the module is quite high up to the temperature of $300{ }^{\circ} \mathrm{C}$. It is shown in the analysis. At the interest range of temperature (from $300{ }^{\circ} \mathrm{C}$ to $750{ }^{\circ} \mathrm{C}$ ) produced module reached very good results. Relative error does not exceed $0.350 \%$ and from the temperature $750{ }^{\circ} \mathrm{C}$ to the maximum results are even better. Relative error is lower than $0.150 \%$. Comparing polynomial approximation itself and real module results the module is better for all thermocouple types. The module seems to be suitable part of calibration system for jet engine exhaust gas temperature measurement system. So other work rises and that is to apply correction of a cold junction and to integrate it to the whole system.

\section{Acknowledgement}

The work presented in this article has been supported by the Czech Republic Ministry of Defence - University of Defence development program "Research of sensor and control systems to achieve battlefield information superiority".

\section{References}

AD8605 ART: Datasheet [pdf]. Available from: http://www.analog.com/media/ en/technical-documentation/data-sheets/AD8605 8606_8608.pdf. [Accessed: 20th February 2016]

Agilent 34410A and 34411A Multimeters: Manual. [pdf]. Available from: http://cp.literature.agilent.com/litweb/pdf/5989-3738EN.pdf. [Accessed: 21th February 2016]

ATmega32: Datasheet. [pdf]. Available from: http://www.atmel.com/images/ doc2503.pdf. [Accessed: 19th February 2016]

DAC 8830: Datasheet. [pdf]. Available from: http://www.ti.com/lit/ds/ sg1s334c/sgls334c.pdf. [Accessed: 18th February 2016]

Kussior, Z. (2002). Principle of Thrust Creation. Z. Kussior, Www.leteckemotory.cz [Online]. Available from: http://www.leteckemotory.cz/teorie/ teorie-01.php (in Czech). [Accessed: 17th February 2016]

Kreidl, M. (2005). Temperature Measurement: Sensors and Measurement Circuits. 1st ed., BEN - technical literature, Prague. (in Czech).

Nermut, M. (2009). Thermocouple Simulator. BSc. Thesis, Faculty of Electrical Engineering and Communication, Brno University of Technology, (in Czech).

Puncochar, J. (2002). Operational Amplifier in Electronics. 5th ed., BEN technical literature, Prague, (in Czech).

RECOM R-785.0-1.0: Datasheet. [pdf]. Available from: http://www.recom-international.com/pdf/Innoline/R-78xx-1.0.pdf. [Accessed: 20th February 2016]

REF 5050: Datasheet. [pdf]. Available from: http://www.ti.com/lit/ds/sbos410f/ sbos410f.pdf. [Accessed: 18th February 2016]

Thermal Analysis - theory. [Online]. Available from: http://www.vscht.cz/met/ stranky/vyuka/labcv/labor/fm_termicka_analyza/teorie.htm (in Czech). [Accessed: 3rd May 2013]

Thermocouple Database. [Online]. Available from: http://srdata.nist.gov/its90/ main/. [Accessed: 3rd May 2013] 